\title{
Bifidobacterial enolase, a cell surface receptor for human plasminogen involved in the interaction with the host
}

Correspondence

Patrizia Brigidi

patrizia.brigidi@unibo.it

Received 2 March 2009

Revised 29 May 2009

Accepted 30 June 2009

\author{
Marco Candela, ${ }^{1}$ Elena Biagi, ${ }^{1}$ Manuela Centanni, ${ }^{1}$ Silvia Turroni, ${ }^{1}$ \\ Manuela Vici, ${ }^{2}$ Francesco Musiani, ${ }^{3}$ Beatrice Vitali, ${ }^{1}$ Simone Bergmann, ${ }^{4}$ \\ Sven Hammerschmidt ${ }^{5}$ and Patrizia Brigidi ${ }^{1}$ \\ ${ }^{1}$ Department of Pharmaceutical Sciences, CIRB-centre for Biotechnology, University of Bologna, \\ Italy \\ ${ }^{2}$ Department of Experimental Pathology, University of Bologna, Italy \\ ${ }^{3}$ Department of Agro Environmental Science and Technology, University of Bologna, Italy \\ ${ }^{4}$ Department of Microbial Pathogenicity, Helmholtz Centre for Infection Research GmbH, \\ Braunschweig, Germany \\ ${ }^{5}$ Department Genetics of Microorganisms, Ernst Moritz Arndt University Greifswald, Greifswald, \\ Germany
}

\begin{abstract}
The interaction with the host plasminogen/plasmin system represents a novel component in the molecular cross-talk between bifidobacteria and human host. Here, we demonstrated that the plasminogen-binding bifidobacterial species $B$. longum, $B$. bifidum, $B$. breve and $B$. lactis share the key glycolytic enzyme enolase as a surface receptor for human plasminogen. Enolase was visualized on the cell surface of the model strain B. lactis BI07. The His-tagged recombinant protein showed a high affinity for human plasminogen, with an equilibrium dissociation constant in the nanomolar range. By site-directed mutagenesis we demonstrated that the interaction between the $B$. lactis $\mathrm{BlO} 7$ enolase and human plasminogen involves an internal plasminogen-binding site homologous to that of pneumococcal enolase. According to our data, the positively charged residues Lys-251 and Lys-255, as well as the negatively charged Glu-252, of the B. lactis BI07 enolase are crucial for plasminogen binding. Acting as a human plasminogen receptor, the bifidobacterial surface enolase is suggested to play an important role in the interaction process with the host.
\end{abstract}

\section{INTRODUCTION}

Bifidobacteria represent one of the most important healthpromoting groups of human intestinal microbiota (Schell et al., 2002; Ventura et al., 2009). Even though numerous health-promoting activities have been related to the presence of bifidobacteria in the human gastrointestinal tract (Guarner \& Malagelada, 2003), knowledge of the mechanisms of interaction with the host is still in its infancy. The understanding of the Bifidobacterium-host interaction process, as well as its impact on human health, could be clarified by the identification and characterization of the bacterial proteins involved. In particular, representing the first line of contact with the intestinal epithelium,

Abbreviations: 2-PGE, 2-phosphoglycerate; EACA, $\varepsilon$-aminocaproic acid; PEP, phosphoenolpyruvate; Plg, plasminogen.

The GenBank/EMBL/DDBJ accession number for the enolase sequence of $B$. lactis BI07 is DQ117970. the proteins of the bacterial cell surface may play a critical role in the early interaction between microbes and the host (Klijn et al., 2005). Recently, a proteomic approach identified five highly conserved cytoplasmic proteins in the cell wall fraction of Bifidobacterium lactis BI07 as putative human plasminogen $(\mathrm{Plg})$ receptors: DnaK, glutamine synthetase, enolase, bile salt hydrolase and phosphoglycerate mutase (Candela et al., 2007). Plg is the zymogen of plasmin, a trypsin-like serine protease with a broad substrate specificity. Plg is a single-chain glycoprotein with a molecular mass of $92 \mathrm{kDa}$ and comprises an Nterminal pre-activation peptide $(\sim 8 \mathrm{kDa})$, five consecutive disulfide-bonded triple-loop kringle domains (K1-5), and a serine-protease domain containing the catalytic triad (Vassalli et al., 1991). It is produced mainly by hepatocytes; however, other tissue sources for Plg synthesis have been identified, including the intestine (Zhang et al., 2002). The active form of plasmin is involved in fibrinolysis (Collen \& 
Verstraete, 1975), homeostasis and degradation of the extracellular matrix and basement membrane (Saksela \& Rifkin, 1988). The capability to intervene with the $\mathrm{Plg} /$ plasmin system is a strategy for host colonization shared by several pathogens and commensals of the human gastrointestinal tract (Parkkinen \& Korhonen, 1989; Schaumburg et al., 2004; Lähteenmäki et al., 2005; Sijbrandi et al., 2005; Bergmann \& Hammerschmidt, 2007; Hurmalainen et al., 2007; Candela et al., 2008). With the recruitment of human $\mathrm{Plg}$ on the bacterial cell surface, and its subsequent conversion to plasmin, the micro-organism acquires a surface-associated and host-derived proteolytic activity, useful for facilitating the migration across physical and molecular barriers and for responding to the nutritional demands during the colonization process (Lähteenmäki et al., 2005). Several bacterial receptors for human Plg have been characterized (Lähteenmäki et al., 2001). Interestingly, most of them have other important functions besides Plg binding, such as adhesion, movement, enzymic activity or nutrient uptake. In particular, glycolytic enzymes including glyceraldehyde-3-phosphate dehydrogenase and enolase interact with Plg, as shown for different bacterial species (Bergmann \& Hammerschmidt, 2007). In spite of the absence of peptides required for secretion and membrane anchorage, these key cytoplasmic enzymes are displayed on the bacterial cell surface, where they acquire a secondary 'moonlighting' function (Jeffery, 1999) that has been shown to be important in the bacteria-host interaction process.

A dose-dependent human Plg-binding activity was recently demonstrated in four bifidobacterial strains belonging to the species B. lactis, B. bifidum and B. longum (Candela et al., 2007). The complete inhibition of Plg recruitment on the bifidobacterial cell surface in the presence of the lysine analogue $\varepsilon$-aminocaproic acid (EACA) suggested that the binding of human Plg to these bifidobacteria was strongly dependent on lysine residues of surface-exposed $\mathrm{Plg}$ receptors (Candela et al., 2007). However, bifidobacterial receptors for human Plg have never been characterized. In an attempt to provide insights into the interaction between bifidobacteria and human-derived Plg, we assessed here the role of the bifidobacterial enolase as a surface-displayed Plg receptor in four bifidobacterial species with Plg-binding activity. The localization of enolase on the bacterial cell surface was demonstrated by immunoelectron microscopy in the model strain B. lactis BI07. The recombinant Histagged enolase protein was purified and its Plg-binding activity was characterized with respect to the dissociation constant and the mechanism of Plg binding. By functioning as a surface receptor for human Plg, enolase may play an important role in the bifidobacterial-host interaction process.

\section{METHODS}

Bacterial strains, media, and growth conditions. Four bifidobacterial strains were studied. B. bifidum S16 and B. longum S123 were isolated from human faeces, whereas B. breve BBSF and B. lactis BI07 were isolated from dairy products. Bifidobacteria were cultured in MRS medium (Difco) supplemented with $0.05 \%(w / v)$ L-cysteine at $37{ }^{\circ} \mathrm{C}$ in anaerobic conditions, obtained by using Anaerocult A (Merck) in a jar. The cultures were grown for $18 \mathrm{~h}$ until they reached the stationary phase. Escherichia coli strains OneShot TOP10, BL21Star(DE3) and XL10-Gold were cultured at $37{ }^{\circ} \mathrm{C}$ in LuriaBertani (LB) medium with shaking. MagicMedia (Invitrogen) was used for recombinant protein expression. Kanamycin $\left(50 \mu \mathrm{g} \mathrm{ml}^{-1}\right)$ was added as a selective agent when appropriate.

Extraction of bifidobacterial cytoplasmic proteins. Cytoplasmic proteins were extracted from $50 \mathrm{ml}$ bacterial culture in the stationary growth phase. Cells were collected by centrifugation for $10 \mathrm{~min}$ at $3800 \mathrm{~g}, 4{ }^{\circ} \mathrm{C}$ and then washed in $50 \mathrm{mM}$ Tris/HCl $(\mathrm{pH} \mathrm{7.6)}$, resuspended in $500 \mu \mathrm{TE}$ buffer $(50 \mathrm{mM}$ Tris/HCl pH 7.6, $5 \mathrm{mM}$ EDTA) and $50 \mu$ l Complete Protease Inhibitor Solution (Roche) were added. The suspension was sonicated for $8 \mathrm{~min}$, power $30 \mathrm{~W}$, pulse frequency $20 \%$ in a Branson Sonifier 250 and centrifuged for $10 \mathrm{~min}$ at $22000 \mathrm{~g}, 4{ }^{\circ} \mathrm{C}$. The supernatant was collected and centrifuged for $2 \mathrm{~h}$ at $176000 \mathrm{~g}, 4{ }^{\circ} \mathrm{C}$ by using a Beckman Ultracentrifuge L7-55. The supernatant, containing cytoplasmic proteins, was stored at $-20{ }^{\circ} \mathrm{C}$.

Resolution of Bifidobacterium cell wall proteins by 2Delectrophoresis and PIg overlay assay. Experiments were carried out as reported by Candela et al. (2007). Briefly, $40 \mu \mathrm{g}$ bifidobacterial cell wall proteins was resolved by $2 \mathrm{D}$-electrophoresis. Isoelectric focusing was carried out using Immobiline DryStrips with a linear $\mathrm{pH}$ gradient between 4 and $7(7 \mathrm{~cm})$ on an IPGphor system (GE Healthcare) and proteins were separated by SDS-PAGE at $160 \mathrm{~V}$ for $2.5 \mathrm{~h}$. For the Plg overlay assay, the resolved proteins were blotted onto a nitrocellulose membrane (Pure nitrocellulose membrane, BioRad) by using a Trans-Blot Electrophoretic Cell (Bio-Rad). After blocking, the membrane was incubated with $4 \mu \mathrm{g}$ human $\mathrm{Plg} \mathrm{ml} \mathrm{m}^{-1}$ (Sigma-Aldrich) in PBS for $1 \mathrm{~h}$ at $25{ }^{\circ} \mathrm{C}$. Captured Plg was detected by incubating the membrane with goat anti-Plg IgG antibody (Kordia) and a peroxidase-conjugated anti-goat IgG (SigmaAldrich) as secondary antibody. To determine the role of the lysinebinding site(s) in Plg binding, the experiment was repeated in the presence of EACA. Primary and secondary antibody alone did not result in non-specific background binding (data not shown).

Protein identification using MALDI-TOF MS. The selected protein spots were excised from the acrylamide gel and subjected to in-gel tryptic digestion and extraction of peptides (Shevchenko et al., 1996). The extracted peptides were purified with ZipTip (Millipore). Peptide mass fingerprinting maps of tryptic peptides were generated by MALDI-TOF MS with a Voyager-DE Pro Biospectrometry work station (Applied Biosystems), as reported by Candela et al. (2007). Aldente (http://www.expasy.org/tools/aldente) and ProFound (http:// prowl.rockefeller.edu/prowl-cgi/profound.exe) database search algorithms were used for the identification of the proteins.

Electron microscopy and immunoblot analysis. In order to visualize bifidobacterial enolase on the B. lactis BI07 cell surface, we performed pre-embedding immunogold experiments using intact bacterial cells. Bifidobacterial cells recovered from a stationary-phase culture were washed in PBS and adjusted to a concentration of $1 \times 10^{9}$ c.f.u. $\mathrm{ml}^{-1}$. Cells were resuspended in $100 \mu \mathrm{l}$ rabbit polyclonal antipneumococcal enolase antiserum (Bergmann et al., 2003) diluted $1: 250$ in $\mathrm{PBS} / 1 \% \mathrm{BSA}$, and incubated for $1 \mathrm{~h}$ at $25{ }^{\circ} \mathrm{C}$ under constant agitation. After two washes with $1 \mathrm{ml}$ PBS/1 \% BSA, bacteria were resuspended in $25 \mu \mathrm{l}$ anti-rabbit IgG coupled to $10 \mathrm{~nm}$ gold particles (Auro Probe, GE Healthcare) diluted $1: 5$ in PBS/1\% BSA, and incubated for $30 \mathrm{~min}$ at $25^{\circ} \mathrm{C}$ with constant agitation. Bacteria were then collected and washed twice in PBS/1\% BSA and fixed with $2.5 \%$ glutaraldehyde in $0.1 \mathrm{M}$ cacodylate buffer for $4 \mathrm{~h}$ at $4{ }^{\circ} \mathrm{C}$. 
Processing for transmission electron microscopy was carried out as reported by Candela et al. (2007). Electron microscopic experiments were repeated four times. For immunoblot analysis, B. lactis BI07 proteins $(10 \mu \mathrm{g})$ were subjected to SDS-PAGE with $12 \%$ polyacrylamide and blotted onto a nitrocellulose membrane by using a Minitrans-Blot Electrophoretic Cell (Bio-Rad). Post-transfer, the membrane was blocked in a solution of $4 \%$ skim milk (Biolife) in TBS-T $(0.15 \%$ Tween 20 in TBS) and then incubated with rabbit polyclonal anti-streptococcal enolase antiserum (Bergmann et al., 2003). Subsequently, the membrane was washed in TBS-T and incubated with the peroxidase-conjugated anti-rabbit IgG (GE Healthcare). After TBS-T washing, the membrane was incubated with ECL Plus (GE Healthcare), and the signal was detected by using a PhosphorImager Storm system (GE Healthcare).

Cloning, expression and purification of recombinant $B$. lactis BI07 enolase. In order to analyse the nucleotide sequence of the $B$. lactis BI07 enolase gene, chromosomal DNA was used as a template for PCR and the enolase gene was amplified with the primer pair LFEno (5'-GAAACTCACGCCTTTACGGGCGTT-3') and R-FEno (5' TCAAGATACACAACCGTTTTAAGGAGT-3'), designed against the nucleotide regions downstream and upstream of the $B$. longum NCC2705 enolase gene (1299 bp, GeneID:1022550), respectively. The PCR product obtained was cloned into the pCRII-TOPO cloning vector (Invitrogen), following the protocol supplied by the manufacturer, and the DNA insert was sequenced using the primer set T7 and T7-reverse. For cloning and expression, the B. lactis BI07 enolase gene was amplified by PCR using the primer set EnoTOPO-L (5'CACCATGGCAGTAATTGAAAGCGTGT-3') and EnoTOPO-R (5' TCACTTGGCCAGGTACTTCT- $3^{\prime}$ ), and the PCR product was cloned into the expression vector pET200/D-TOPO (Invitrogen) to obtain the construct pENOwt. Cloning and expression of the B. lactis BI07 enolase gene were carried out in E. coli TOP-10 and E. coli BL21Star(DE3) (Invitrogen), respectively. The His-tagged fusion $B$. lactis BI07 enolase was purified by affinity chromatography under native conditions on Ni-NTA resin, according to the manufacturer's instructions (Invitrogen). The purified proteins were dialysed at $4{ }^{\circ} \mathrm{C}$ using Spectra/Por membranes $6000-8000 \mathrm{kDa}$ (Spectrum Laboratories) and $20 \mathrm{mM}$ Tris, $120 \mathrm{mM} \mathrm{NaCl}$ as dialysis buffer. The expression of the His-tagged recombinant protein $\mathrm{His}_{6}$-enolase was verified by Western blot analysis with polyclonal anti-pneumococcal enolase antiserum (Bergmann et al., 2001) and anti-HisTag (Sigma) antibody.

Site-directed mutagenesis. The QuikChange Multi Site-Directed Mutagenesis kit (Stratagene) was used to obtain a mutant plasmid library from pENOwt. Plasmids harbouring mutants of the B. lactis BI07 enolase gene, deleted of nucleotides encoding the C-terminal lysine (pENObs1), mutated in the internal Plg-binding site (pENObs2), or with both the deletion and the internal mutation (pENOdouble), were created. Primer ENOmutBS1 (5' AAGAAGTACCTGGCCTGATGAAAGGGCGAGCTCAACG-3') was designed to replace the $\mathrm{C}$-terminal lysine with a stop codon. Primer ENOmutBS2 (5'-GAGTTCTACAACTTGGGGACCGGCTTGTACCGCTTCGACGG-3') was designed to replace Lys-251 and Lys-255 with leucine, and Glu-252 with glycine, as performed by Bergmann et al. (2003) on Streptococcus pneumoniae enolase. Equal amounts of each primer were added to a $50 \mu \mathrm{l}$ PCR, together with $200 \mathrm{ng}$ pENOwt as DNA template. The mutagenesis reaction was carried out in a thermocycler with a first denaturation step at $95{ }^{\circ} \mathrm{C}$ for $1 \mathrm{~min}$, followed by 30 cycles at $95{ }^{\circ} \mathrm{C}$ for $1 \mathrm{~min}, 55^{\circ} \mathrm{C}$ for $1 \mathrm{~min}$ and $65{ }^{\circ} \mathrm{C}$ for $14 \mathrm{~min}$. The DNA template was removed by $D p n \mathrm{I}$ treatment at $37{ }^{\circ} \mathrm{C}$ for $2 \mathrm{~h}$. The mutant plasmid library was transformed into the E. coli XL10-Gold strain and a number of clones were sequenced to isolate the three mutants. Mutant proteins carrying the desired amino acid substitutions or deletion were expressed and purified as described above.
Enolase activity of bifidobacterial whole cells and purified $B$. lactis BI07 enolase protein. In order to determine the enolase activity of intact bifidobacterial cells, a direct enzyme assay was performed (Pancholi \& Fischetti, 1998). Briefly, $1 \times 10^{9}$ bifidobacterial cells were washed three times in 100 mM HEPES buffer $\mathrm{pH} 7$ and equal amounts were resuspended in reaction buffer [100 mM HEPES (pH 7), $10 \mathrm{mM} \mathrm{MgCl}_{2}, 7.7 \mathrm{mM} \mathrm{KCl,} 3 \mathrm{mM}$ 2-phosphoglycerate (2PGE)] or in control buffer [100 mM HEPES (pH 7), $10 \mathrm{mM} \mathrm{MgCl}_{2}$, $7.7 \mathrm{mM} \mathrm{KCl}$. The bacterial suspensions were incubated for $3 \mathrm{~min}$ at $37{ }^{\circ} \mathrm{C}$ and subsequently centrifuged for $10 \mathrm{~min}$ at $19000 \mathrm{~g}, 4{ }^{\circ} \mathrm{C}$. The supernatants were recovered and centrifuged for a further $10 \mathrm{~min}$ at $19000 \mathrm{~g}, 4{ }^{\circ} \mathrm{C}$. After the second centrifugation step, the supernatants were recovered and phosphoenolpyruvate (PEP) concentration was determined by measuring the absorbance at $240 \mathrm{~nm}$ in a Jasco spectrophotometer (model 7800/V-520). The enzyme activity of the purified His-tagged enolase protein was determined in a single enzyme assay. Briefly, different amounts of purified recombinant Histagged enolase protein were incubated for $3 \mathrm{~min}$ at $37{ }^{\circ} \mathrm{C}$ in reaction buffer containing $15 \mathrm{mM}$ 2-PGE. The release of PEP was measured spectrophotometrically as described above. For kinetics studies, different amounts of 2-PGE $(0.5-15 \mathrm{mM})$ were used in a single enzyme assay carried out with $5 \mu \mathrm{g}$ purified His-tagged enolase protein. The $K_{\mathrm{m}}$ value was calculated from the Lineweaver-Burk plot.

Structural model of B. lactis B107 enolase. The homology model of B. lactis BI07 enolase was calculated as reported by Zambelli et al. (2009). Using the tool BLAST (Altschul et al., 1990, 1997), the amino acid sequence of B. lactis BI07 enolase (Swiss-Prot accession no. Q45RT9) was used to search for bacterial enolase structures with a high identity score. Four enolases with known protein structures were selected: Strep. pneumoniae enolase (PDB code 1W6T), Enterococcus hirae enolase (PDB code 1IYX), Methanococcus jannaschii enolase (PDB code 2PA6), and Escherichia coli enolase (PDB code 1E91). Multiple sequence alignment was carried out using CLUSTAL W (Thompson et al., 1994). The prediction of the B. lactis BI07 enolase secondary structure was carried out using the JPRED tool (Cuff et al., 1998) and the alignment was manually optimized based on the secondary structure information. Model structure was calculated with the program MODELler 9v5 (Marti-Renom et al., 2000), using the above indicated enolases as templates. The best model was selected on the basis of the lowest value of the MODELLER objective function. Structure validation was performed using PROCHECK (Laskowski et al., 1993). The program UCSF Chimera (Pettersen et al., 2004) was used for protein visualization.

Plg-binding analysis. Human Plg (Sigma-Aldrich) was biotinylated using the EZ-Link Micro Sulfo-NHS-SS Biotinylation kit (Pierce), following the manufacturer's instructions. The solid-phase Plgbinding assay was performed as previously described by SandersonSmith et al. (2006, 2007). Microtitre plates (96-well; OptiPlate-96, Perkin Elmer) were coated with $150 \mathrm{nM}$ recombinant enolase $(50 \mu \mathrm{l}$ in $0.1 \mathrm{M} \mathrm{NaHCO}_{3}$ ) and incubated at $4{ }^{\circ} \mathrm{C}$ overnight. After washing with PBS, the plates were blocked with $200 \mu$ BSA $2 \%$ in PBS for $1 \mathrm{~h}$ at $37{ }^{\circ} \mathrm{C}$. After three PBS washes, increasing concentrations of biotinylated Plg in PBS (2, 6, 18, 36, 55, 110, 166 and $250 \mathrm{nM})$ were added to the plates, in the presence or absence of a 50 -fold molar excess of unlabelled Plg. Plg was allowed to bind to immobilized proteins for $2 \mathrm{~h}$ at room temperature, then the plates were washed three times with PBS, and $50 \mu \mathrm{l}$ ExtrAvidin horseradish-peroxidaseconjugated antibodies (Sigma-Aldrich), diluted 1:5000 in PBS/1\% BSA, was added to each well. Plates were incubated for $2 \mathrm{~h}$ at $25{ }^{\circ} \mathrm{C}$ and washed four times with PBS and $0.05 \%$ Tween 20. One hundred microlitres of Chemiluminescent Peroxidase Substrate for ELISA (Sigma-Aldrich) was added to each well and luminescence was read using a Victor ${ }^{3} \mathrm{~V} 1420$ Multilabel Counter scanner (Perkin Elmer) and the software Wallac 1420 WorkStation. As a negative control for Plg binding, BSA-coated plates were utilized. For each of the recombinant 
proteins, Plg-binding experiments were repeated four times, whereas for a given Plg concentration, each measurement was repeated in triplicate. To assess the involvement of lysine residues in the enolase$\mathrm{Plg}$ interaction, experiments were repeated in the presence of $0.5 \mathrm{M}$ EACA. For analysis, data were normalized against the highest and lowest luminescence values, and nonlinear regression analysis was carried out using Graph Pad Prism (version 5.0, Graph Pad Software). For calculation of the equilibrium dissociation constant $\left(K_{\mathrm{D}}\right)$ oneand two-site binding analysis was performed and the best-fit curve was chosen.

\section{RESULTS}

\section{Enolase is a conserved putative Plg receptor in Bifidobacterium}

In order to screen the putative surface Plg receptors in Bifidobacterium, the cell wall fractions from the $\mathrm{Plg}$ binding strains B. longum S123, B. bifidum S16 (Candela et al., 2007) and B. breve BBSF (data not shown) were purified and a Plg overlay assay was carried out. To this end, cell wall proteins were resolved in a two-dimensional gel, immobilized on a nitrocellulose membrane, incubated with human $\mathrm{Plg}$, and probed with anti-Plg antibody to identify bound Plg (Fig. 1). For each strain, the coordinates of the major putative Plg-binding proteins detected could be matched to a protein spot on the replica gel stained for proteins. Plg binding was completely inhibited in the presence of EACA (data not shown). Among the putative Plg-binding proteins, two proteins with an apparent molecular mass of 70 and $50 \mathrm{kDa}$ and a pI of 4.5 and 4.7, respectively, were found to be conserved in the different bifidobacterial strains analysed. For each strain, the corresponding spots were excised from the gel and subjected to trypsin digestion and MALDI-TOF MS analysis for protein identification. The peptide fingerprints obtained were scanned with the searching tools Aldente and ProFound, and an unambiguous identification was obtained: the protein of $70 \mathrm{kDa}$ and $\mathrm{pI} 4.5$ was identified as DnaK and the protein of $50 \mathrm{kDa}$ and pI 4.7 as enolase. DnaK and enolase had been previously identified as putative Plg receptors in a cell wall fraction of the Plgbinding strain B. lactis BI07 (Candela et al., 2007). To investigate the role of bifidobacterial enolase as a receptor for human Plg, B. lactis BI07 was selected as model strain.

\section{Localization of enolase protein on the $B$. lactis BI07 cell surface}

At first, the distribution of enolase in cytoplasmic and cell wall fractions of B. lactis BI07 was evaluated by a Western blot experiment carried out with a cross-reactive polyclonal anti-pneumococcal enolase antiserum (anti-Eno) (Bergmann et al., 2003). Enolase was detected in both the cytoplasmic and cell wall fractions of B. lactis BI07 (Fig. 2). In order to visualize the enolase protein on the B. lactis BI07 cell surface, an immunoelectron microscopy experiment was carried out. Intact B. lactis BI07 cells were incubated under pre-embedding labelling conditions with

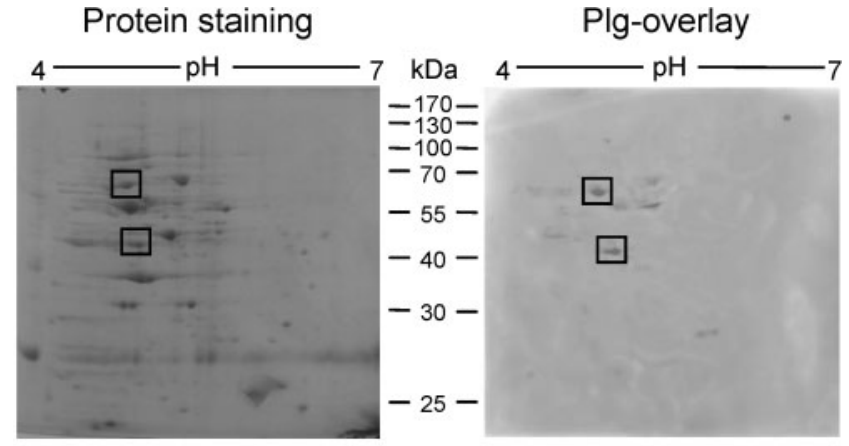

(a)
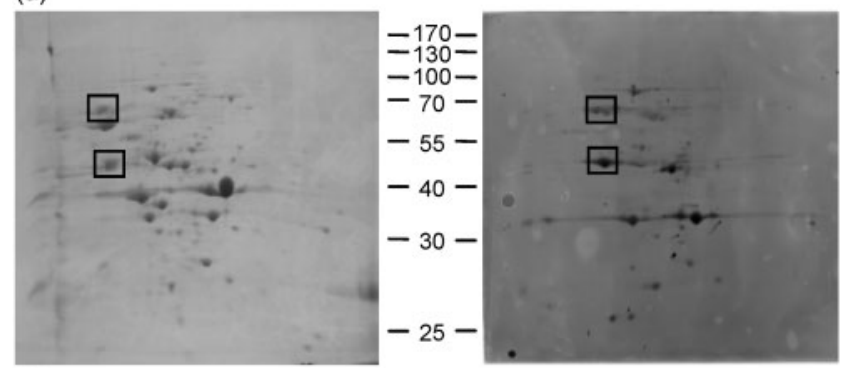

(b)
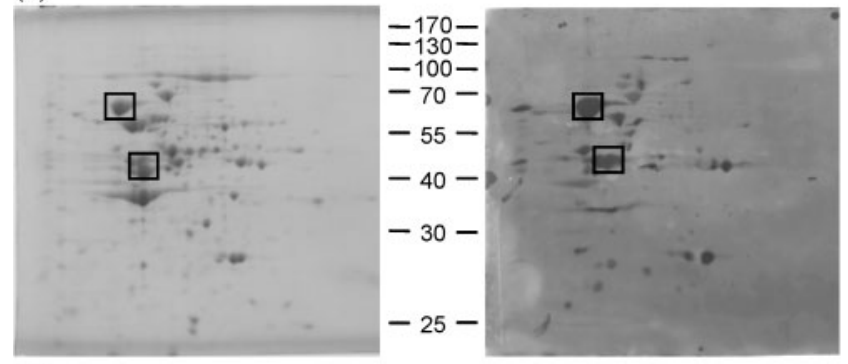

(c)

Fig. 1. Plg overlay assay carried out with the cell wall fraction of B. longum S123 (a), B. bifidum S16 (b) and B. breve BBSF (c). For each strain, the 2D-gel stained for proteins and the replicate 2D-gel used for Plg overlay are shown. Four micrograms Plg per ml was applied as the Plg overlay. Plg-binding proteins were detected with anti-Plg antibody and peroxidase-conjugated secondary antibody. The black squares indicate two proteins with an apparent molecular mass of 70 and $50 \mathrm{kDa}$ and a pl of 4.5 and 4.7 , which are conserved among the different bifidobacterial strains.

the anti-Eno antiserum followed by the secondary antibody labelled with $10 \mathrm{~nm}$ gold particles. Analysis of ultrathin sections at a magnification of $\times 22000$ (Fig. 3) detected the enolase (black dots) directly in the bacterial cell wall region. Non-specific binding of the secondary antibody was not detected (data not shown). The binding pattern of the anti-Eno antiserum suggests either that the distribution of enolase is in the form of a cluster, or that its epitopes are not uniformly exposed on the cell surface. The enzyme functionality of the surface enolase was evaluated by monitoring the conversion of 2-PGE to PEP, when supplied to viable bifidobacterial cells. Intact cells of $B$. lactis BI07 showed a dose-dependent enolase activity (data not shown). 
(a)

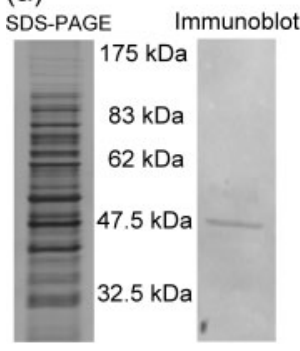

(b)

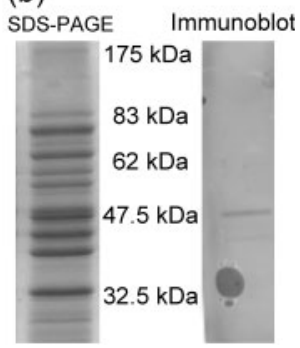

Fig. 2. Immunoblot analysis using anti-enolase antiserum of cytoplasmic (a) and cell wall (b) fractions of B. lactis BI07 resolved by SDS-PAGE.

\section{Analysis of Plg binding to B. lactis BI07 enolase}

In order to characterize the Plg-binding activity of $B$. lactis BI07 enolase, the gene was sequenced, cloned, and the recombinant $\mathrm{His}_{6}$-tagged enolase protein was purified by affinity chromatography. The nucleotide sequence of $B$. lactis BI07 enolase (GenBank accession no. DQ117970) revealed $98 \%$ identity to the enolase gene of B. longum NCC2705 (GenBank accession no. AE014295). In Fig. 4 we show the dose-dependent enzymic activity for the recombinant $\mathrm{His}_{6}$-tagged $B$. lactis $\mathrm{BI07}$ enolase. 2-PGE was converted to PEP with a specific activity of $1.35 \mu \mathrm{mol}$ PEP synthesized per min per $\mathrm{mg}$ protein. These data indicate that $B$. lactis $\mathrm{BI} 07$ enolase was purified in the native $3 \mathrm{D}$ structure. To evaluate the specific Plg-binding activity of $B$. lactis BI07 enolase, a solid-phase Plg-binding assay (Sanderson-Smith et al., 2007) was carried out. The

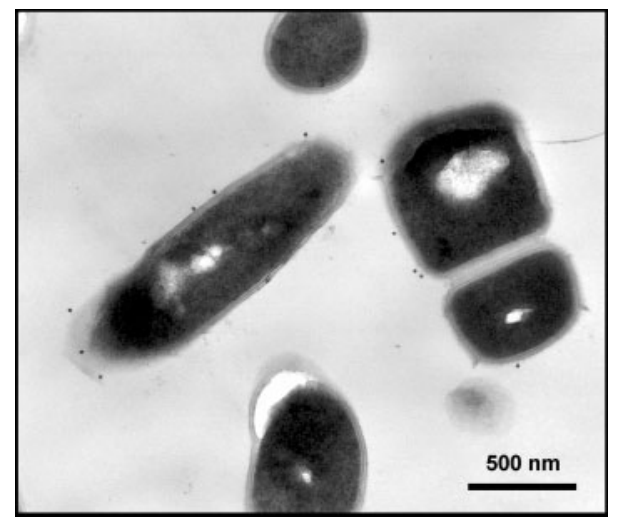

Fig. 3. Immunoelectron microscopic localization of enolase on the cell wall of $B$. lactis BI07. Enolase was detected on the bacterial surface by anti-enolase antiserum and a secondary antibody coupled to $10 \mathrm{~nm}$ gold particles in pre-embedding experiments. An ultrathin section of $B$. lactis $\mathrm{Bl} 07$ cells at a magnification of $\times 22000$ shows enolase (black dots) localized directly in the cell wall region.

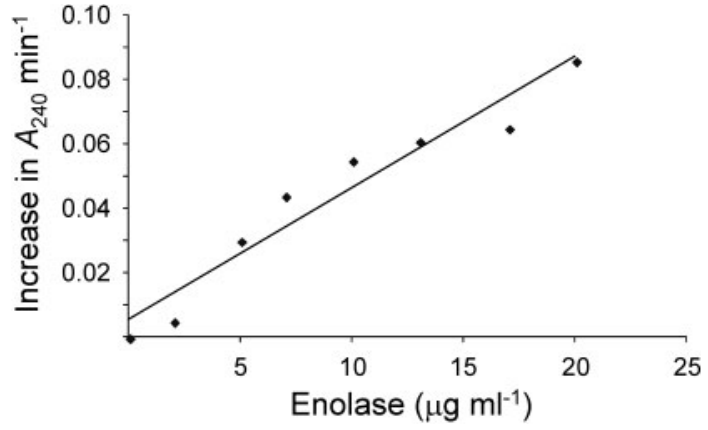

Fig. 4. Enzymic activity of the recombinant $\mathrm{His}_{6}$-enolase of $B$. lactis BI07. The activity was determined using a direct enzyme assay: different amounts of the purified recombinant $\mathrm{His}_{6}$-enolase were incubated with $15 \mathrm{mM}$ 2-PGE. The release of PEP was evaluated by measuring the increase in absorbance at $240 \mathrm{~nm}$.

saturation binding analysis of biotinylated Plg to immobilized recombinant $B$. lactis BI07 enolase is reported in Fig. 5. Non-specific binding was determined in the presence of a 50-fold molar excess of unlabelled Plg, and specific binding was calculated by subtracting non-specific binding from the total binding obtained at each concentration of biotinylated Plg. As a negative control, BSAcoated wells were utilized. According to our data, Plg binding to immobilized enolase was dose-dependent and saturable binding was achieved with $250 \mathrm{nM}$ Plg. The bestfit nonlinear regression analysis allowed calculation of an equilibrium dissociation constant $\left(K_{\mathrm{D}}\right)$ for the interaction of enolase with Plg of $42 \mathrm{nM}$. The binding was completely inhibited in the presence of $0.5 \mathrm{M}$ EACA, proving the crucial role of enolase lysine(s) in $\mathrm{Plg}$ binding.

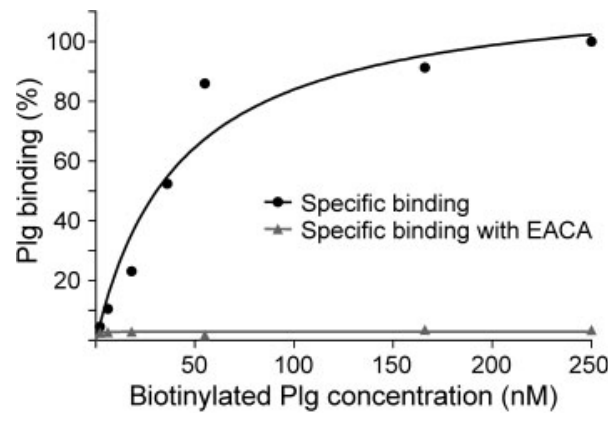

Fig. 5. Saturation binding analysis of biotinylated Plg to immobilized recombinant His-tagged B. lactis BI07 enolase. Specific Plg binding $(\bullet)$ was calculated at each concentration of biotinylated Plg by subtracting non-specific binding obtained in the presence of a 50-fold molar excess of unlabelled Plg from total binding. A one-site hyperbolic binding function was fitted to the data and the $K_{\mathrm{D}}$ determined. The experiment was repeated in the presence of the lysine analogue EACA (0.5 M, grey triangles). 


\section{Homology model of B. lactis BI07 enolase and identification of the putative Plg-binding sites}

In an attempt to identify the putative Plg-binding site(s) of B. lactis BI07 enolase, a homology model of the protein was generated using the coordinates of four enolases of known structure: the enolases of Strep. pneumoniae (PDB code 1W6T) and Enterococcus hirae (PDB code 1IYX), which share $55 \%$ identity with $B$. lactis BI07 enolase, and the enolases of Escherichia coli (PDB code 1E9I) and $M$. jannaschii (PDB code 2PA6), which show $52 \%$ identity with B. lactis BI07 enolase (Fig. 6a). In Fig. 6(b), a model of the $B$. lactis BI07 enolase dimer is represented. The Ramachandran Plot analysis (Willard et al., 2003) of the model for B. lactis BI07 enolase indicated a good stereochemical quality (data not shown). The monomer consists of two domains: the N-terminal domain contains a three-stranded antiparallel $\beta$-sheet followed by six $\alpha$ helices, and the C-terminal domain is composed of an $\alpha /$ $\beta$-barrel structure. B. lactis BI07 enolase possesses a Cterminal lysine at amino acid position 432, which constitutes a homologue of the pneumococcal Plg-binding site BS1 (Bergmann et al., 2003). In order to evaluate whether the surface loop L3 of B. lactis BI07 enolase contained a peptide region homologous to the internal Plgbinding site BS2, located on the surface-exposed loop L3 of Strep. pneumoniae enolase (residues 248-256; Ehinger et al., 2004), the protein structures were superimposed. A $0.4 \AA$ $(0.04 \mathrm{~nm})$ root-mean-square distance (r.m.s.d.) between the $\mathrm{C} \alpha$ atom positions of the $B$. lactis $\mathrm{BI} 07$ and pneumococcal enolases demonstrated an overall structural similarity between these two proteins. In particular, the enolases of B. lactis BI07 and Strep. pneumoniae shared a significant structural similarity in the loop L3 (r.m.s.d. of $0.64 \AA, 0.064 \mathrm{~nm}$ ) (Fig. 6c). Residues 248-256 within the L3 region of $B$. lactis BI07 enolase and the BS2 region of pneumococcal enolase displayed high structural homology.

\section{Impact of BS1 and BS2 homologues on PIg binding to $B$. lactis B107 enolase}

In order to determine the role of the putative Plg-binding sites BS1 and BS2 of B. lactis BI07 enolase in Plg binding, three genetic mutants of the corresponding enolase (eno) gene were constructed: (i) the eno ${ }^{\mathrm{BS} 1}$ mutant gene, deleted of the BS1 pneumococcal homologue, obtained by the deletion of the codon encoding the C-terminal lysyl residue at position 432; (ii) the $e n o^{\mathrm{BS} 2}$ mutant gene, obtained by site-directed mutagenesis of the amino acids homologous to those that were previously demonstrated to be essential in Plg-binding to the BS2 site of the pneumococcal enolase (Bergmann et al., 2003; Ehinger et al., 2004), 251 $($ Lys $\rightarrow$ Leu), 252 (Glu $\rightarrow$ Gly) and 255 (Lys $\rightarrow$ Leu); and (iii) the eno ${ }^{\text {double }}$ mutant gene constructed by deleting the C-terminal lysine from the $e n o^{\mathrm{BS} 2}$ mutant. The recombinant His-tagged enolase ${ }^{\mathrm{BS} 1}$, enolase ${ }^{\mathrm{BS} 2}$ and enolase double proteins were purified and their specific Plg-binding activity was evaluated in a saturation binding analysis of biotinylated Plg to the immobilized recombinant proteins (Fig. 7). The interaction of enolase ${ }^{\mathrm{BS} 1}$ with Plg was dosedependent and saturable, with a $K_{\mathrm{D}}$ of about $46.2 \mathrm{nM}$, a value comparable to that shown by the wild-type $B$. lactis $\mathrm{BI} 07$ enolase protein. In contrast, neither enolase ${ }^{\mathrm{BS} 2}$ nor enolase $^{\text {double }}$ showed specific and saturable interaction with human Plg, proving the crucial role of the BS2 homologue in $\mathrm{Plg}$ binding to B. lactis $\mathrm{BI} 07$ enolase.

\section{DISCUSSION}

Plg-binding bifidobacterial strains belonging to the human-associated species B. longum, B. bifidum and $B$. breve (Ventura et al., 2007), as well as the Plg-binding probiotic strain B. lactis BI07 (Candela et al., 2007), share the enolase enzyme as one of their putative surface Plg receptors. Enolase is an essential glycolytic enzyme catalysing the formation of PEP from 2-PGE. Localized on the cell surface, it is one of the best-characterized human Plg receptors in prokaryotes and eukaryotes (Pancholi \& Fischetti, 1998; Bergmann et al., 2001; Crowe et al., 2003; Schaumburg et al., 2004; Lähteenmäki et al., 2005; Antikainen et al., 2007b; Knaust et al., 2007). A single enolase gene is present in the published genomes of the bifidobacterial species $B$. animalis subsp. lactis (accession no. NC_011835), B. longum (accession no. NC_004307), B. longum subsp. infantis (accession no. NC_011593), B. adolescentis (accession no. NC_008618) and B. bifidum (accession no. NZ_ABQP00000000). Thus, analogously to Streptococcus pyogenes, Strep. pneumoniae and Staphylococcus aureus (Antikainen et al., 2007a), the same enolase gene product is both an essential glycolytic enzyme in the cytoplasm and, localized on the cell surface, a receptor for human Plg. As reported for several prokaryotes and eukaryotes that display enolase on the cell surface (Pancholi, 2001), the bifidobacterial enolase lacks either predicted or detectable protein-sorting elements for secretion and anchorage onto the bacterial cell wall. The mechanisms of secretion and surface localization of this essential glycolytic enzyme are still under debate. Recently for Strep. pneumoniae, scavenging of cytoplasmic proteins released through allolysis was proposed to account for the presence of enolase on the cell surface (Claverys \& Havarstein, 2007). On the other hand, according to Boël et al. (2004), the export of enolase may depend on the modification of the enzyme by covalent binding of 2-PGE to Lys-341. The role of enolase as a surface Plg receptor was further studied using B. lactis BI07 as a model strain. In a Western blot analysis we confirmed that B. lactis BI07 enolase is present in the cytoplasm and in the cell wall fractions. Moreover, providing direct evidence for the presence of enolase on the bifidobacterial cell surface, enolase was visualized on the cell surface of B. lactis BI07 by immunoelectron microscopy. Similarly to Strep. pyogenes (Pancholi \& Fischetti, 1998), Strep. pneumoniae (Kolberg et al., 2006) and Strep. suis (Esgleas et al., 2008), the B. lactis BI07 enolase is displayed on the bacterial cell surface 
(a)

BI07

$10 \quad 20 \quad 30$

I I I I I I I 10

MAVIESVYARQILDSRGNPTVQVVLDTEDGAQGLGLVPSGASTGEAEAWERRDGDKSVYGGKGVLNAVKAVNEVIAPKVIGMDAADQRALDDLMIELDGTPNK

1 IYX -----MSI I TDVYARE ILDSRGNPTIEVEVYTESGAFGRGMVSGASTGEYEAVELRDGDKARYGGKGVTKAVDNVNNI IAEAII GYDVRDQMAIDKAMIALDGTPNK

1W6T MRGSHHHHHHMSII TDVYAREVLDSRGNPTLEVEVYTESGAFGRGMVPSGASTGEHEAVELRDGDKSRYGGLGTQKAVDNVNNIIAEAI IGYDVRDQQAIDRAMIALDGTPNK

2 PA6 ---MLYNMDERFEI KDIVAREVIDSRGNPTVEVEVI TKGNGYGSAIVPSGASTGTHEALELRDKEK-RFGGKGVLMAVENVNSI IRPEILGYDARMQREIDTIMIELDGTPNK

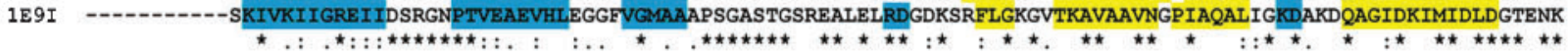

$\begin{array}{llllllllll}110 & 120 & 130 & 140 & 150 & 160 & 170 & 180 & 190 & 200\end{array}$ $\begin{array}{ccccccc}\text { I } & \text { I } & \text { I } & 1 & 1 & 1 & 1\end{array} \mid$ BI07 GKLGANAILGVSLAALYASAESAGLPLYRYIGGTN----GHILPVPNMNIMNGGAHADFATDIQEYMISPYGFDTYSEALRAGVEVYHTLKNVLKKE-GLNTG-LGDEGGFAP
1 IYX GKLGANAILGVSIAVARAAADYLEVPLYHYLGGFN----TKVLPTPMNIINGGSHADNSIDFQEFMIMPVGAPTFKEALRMGAEVFHALAAILKSR-GLATS-VGDEGGFAP 1W6T GKLGANAILGVSIAVARAAADYLEIPLYSYLGGEN----TKVIPTPMNI INGGSHSDAPIAEOERILPVGAPTFKEALRYGAEI FHALKKILKSR-GLETA-VGDEGGEAP 2PA6 SRLGANAILAVSLAVAKAAAATAKIPLYKYLGGFN----SYVMPVPMNVINGGKHAGNDLDLQEFMIMPVGATSISEAVRMGSEVYHVLKNVILEKYGKNAVNVGDEGGFAP 1E9I SKFGANAILAVSLANAKAAAAAKGMPLYEHIAELNGTPGKYSMPVPMNI INGGEHADNNVDIQEFMIQPVGAKTVKEAIRMGSEVFHHLAKVLKAK-GMNTA-VGDEGGYAP

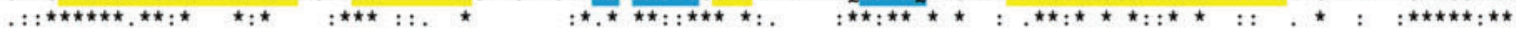

270

280

290

300

310

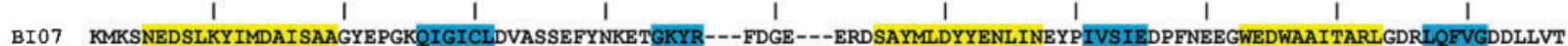

1 IYX NLGSNEEGFEVIIEAIEKAGYVPGKDVVLAMDAASSEFYDKEKGVYVL-ADSGE--GEKTTDEMIKFYEELVSKYPI ISIEDGLDENDWDGFKKLTDVLGDKVQLVGDDLFVT 1W6T RFEGTEDGVETILAAIEAAGYVPGKDVFLGFDCASSEFYDKERKVYDYTKFEGEGAAVRTSAEQIDYLEELVNKYPIITIEDGMDENDWDGWKALTERLGKKVQLVGDDFFVT 2PA6 PLKTSREALDLLTESVKKAGYED--EVVFALDAAASEFY-KD-GYYYV-----EG-KKLTREELLDYYKALVDEYPIVSIEDPFHEEDFEGFAMI TKEL--DIQIVGDDLFVT 1E9I NLGSNAEALAVIAEAVKAAGYELGKDITLAMDCAASEFY-KD-GKYVL---AGEGNKAFTSEEFTHFLEELTKQYPIVSIEDGLDESDWDGFAYQTKVLGDKIQLVGDDLFVT

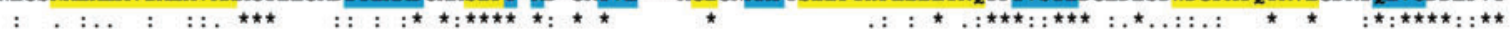

$\begin{array}{llllllllllll}320 & 330 & 340 & 350 & 360 & 370 & 380 & 390 & 400 & 410 & 420 & 430\end{array}$

BI07 NPARLQKAIDLGAANSLLVKLNQIGSVTETLDAIELATANGYTSMVSHRSGETPDTTISDLAVAKNTRQIKTGAPARGERVAKYNRLLEIEEELGSTAQYAGYSAFKACKKYLAK 1 IYX NTQKLSEGIEKGIANSILIKVNQIGTLTETFEAIEMAKEAGYTAVVSHRSGETEDSTISDIAVATNAGQIKTGSLSRTDRIAKYNQLLRIEDQLGEVAEYKGLKSFYNLKAA--1W6T NTDYLARGIQEGAANSILIKVNQIGTLTETFEAIEMAKEAGYTAVVSHRSGETEDSTIADIAVATNAGQIKTGSLSRTDRIAKYNQLLRIEDQLGEVAEYRGLKSFYNLKK-----

2PA6 NVERLRKGIEMKAANALLLKVNQIGTLSEAVDAAQLAFRNGYGVVVSHRSGETEDTTIADLSVALNSGQIKTGAPARGERTAKYNQLIRIEQELG-LSKYAGRN-FRCPF-----

1E9I NTKILKEGIEKGIANSILIKFNQIGSLTETLAAIKMAKDAGYTAVISHRSGETEDATIADLAVGTAAGQIKTGSMSRSDRVAKYNQLIRIEEALGEKAPYNGRKEIKGQA------

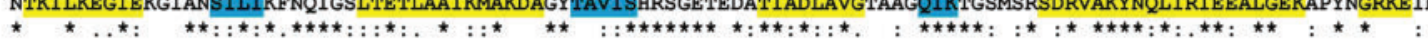
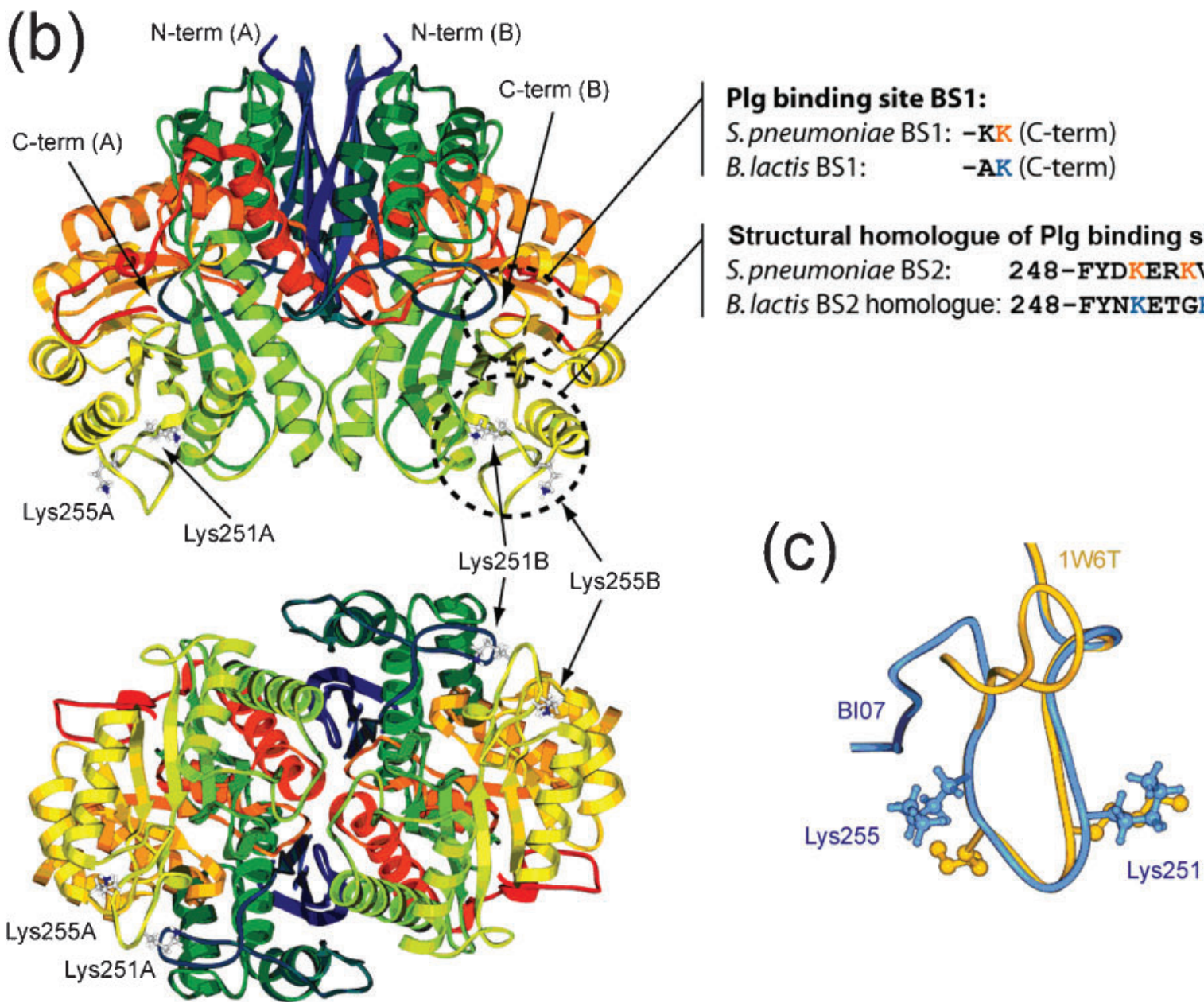
Fig. 6. (a) Multiple sequence alignment of the sequences of Bifidobacterium lactis BI07 (BI07), Enterococcus hirae (1IYX), Streptococcus pneumoniae (1W6T), Methanococcus jannaschii (2PA6) and Escherichia coli (1E91) enolases, with the secondary structure indication ( $\alpha$-helix, yellow; $\beta$-strand, cyan) derived from the JPRED prediction for B. lactis BI07 enolase and from the PDB structure for all the remaining sequences. (b) Ribbon scheme of dimeric B. lactis BI07 enolase model structure, derived using the sequence alignment reported in (a). In the bottom image the ribbons are rotated $90^{\circ}$ around the long horizontal axis. Ribbons are coloured from blue, in the proximity of the $\mathrm{N}$-terminus, to red at the C-terminus. (c) Detailed view of the superimposed L3 regions of $B$. lactis BI07 enolase (blue) and pneumococcal enolase (yellow). Lysines 251 and 255 and the pneumococcal homologue lysines 251 and 254, crucial for Plg binding, are represented in ball and stick notation. The molecular graphic images were produced using the UCSF Chimera package.

with relatively low abundance. The ability of intact $B$. lactis BI07 cells to convert 2-PGE to PEP in a direct enzyme assay demonstrated that the surface enolase still retains its

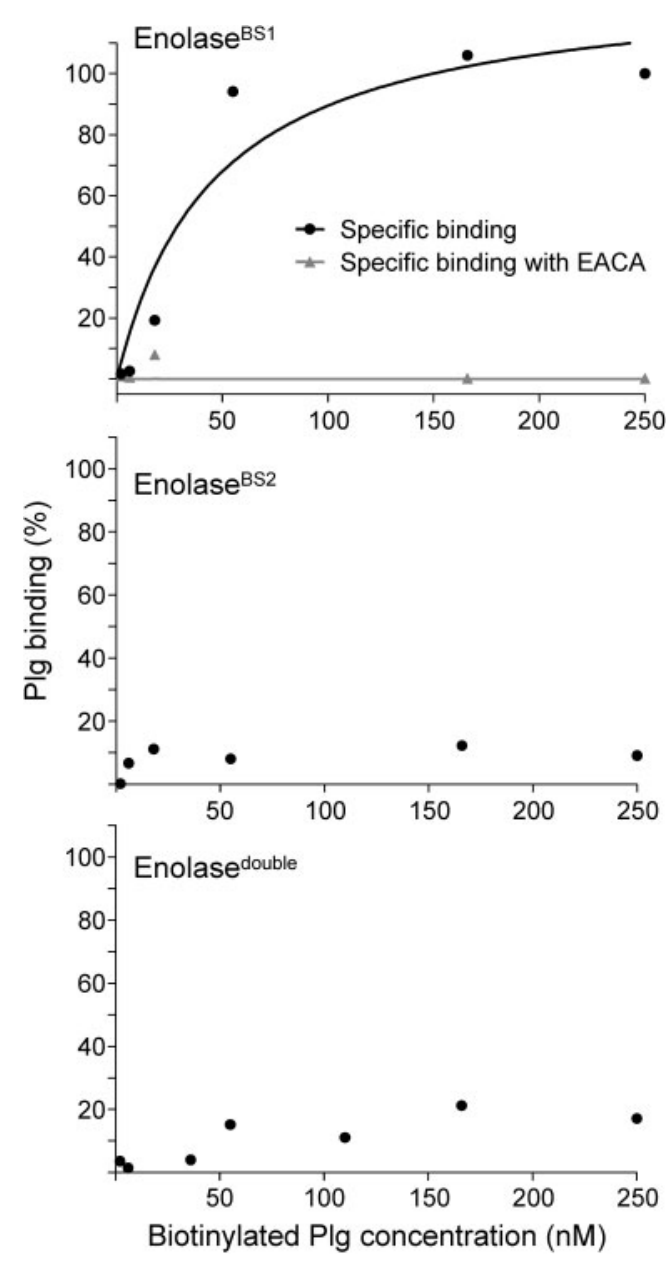

Fig. 7. Saturation binding analysis of biotinylated Plg to immobilized recombinant His-tagged $B$. lactis BI07 Enolase ${ }^{\mathrm{BS} 1}$, Enolase $^{\mathrm{BS} 2}$ and Enolase ${ }^{\text {double }}$ proteins. At each concentration of biotinylated Plg, specific binding $(\bullet)$ was calculated by subtracting the non-specific binding obtained in the presence of a 50 -fold molar excess of unlabelled Plg from the total binding. For Enolase $^{\mathrm{BS} 1}$, a one-site hyperbolic binding function was fitted to the data and the $K_{\mathrm{D}}$ determined. The experiment was repeated in the presence of the lysine analogue EACA ( $0.5 \mathrm{M}$, grey triangles). functional enzyme activity. The His-tagged B. lactis BI07 enolase was purified and characterized with respect to its enzyme activity and, most importantly, its secondary 'moonlighting' function as a $\mathrm{Plg}$ receptor. In a direct enzyme assay, the $K_{\mathrm{m}}$ for 2-PGE was calculated to be $0.73 \mathrm{mM}$. This value is in the range reported for other bacterial enolases, including the Strep. pyogenes (1.492 mM) (Pancholi \& Fischetti, 1998), Strep. pneumoniae (4.5 mM) (Bergmann et al., 2001) and Bacteroides fragilis (0.210 mM) (Sijbrandi et al., 2005) enolases. The affinity of B. lactis BI07 enolase for human Plg was calculated in a saturation binding analysis. The purified His-tagged B. lactis BI07 enolase showed a high affinity for human $\mathrm{Plg}$, with a $K_{\mathrm{D}}$ value in the nanomolar range $(42.8 \mathrm{nM})$. Compared to the eukaryotic enolase, which possesses a $K_{\mathrm{D}}$ value of about $0.1-2 \mu \mathrm{M}$ (Redlitz et al., 1995), the B. lactis BI07 enolase shows a significantly higher affinity for human Plg. On the other hand, in comparison with bacterial enolases from pathogenic micro-organisms, B. lactis BI07 enolase shows a slightly lower affinity to human Plg. Strep. pyogenes, Strep. pneumoniae and Strep. suis enolases demonstrated $K_{\mathrm{D}}$ values for human Plg of 14, 0.55 and $14 \mathrm{nM}$, respectively (Pancholi \& Fischetti, 1998; Bergmann et al., 2003; Esgleas et al., 2008). The best-fit nonlinear regression of data obtained in the saturation binding analysis to $\mathrm{Plg}$ indicated that the $\mathrm{B}$. lactis $\mathrm{BI} 07$ enolase possesses only one site of binding to human Plg. Our data are in general agreement with those reported for Strep. pyogenes (Derbise et al., 2004) and Strep. pneumoniae enolases (Bergmann et al., 2005). However, while in the case of Strep. pyogenes the C-terminal lysines have been indicated as the Plg binding site, for pneumococcal enolase Plg-binding mainly depends on the internal Plg-binding site BS2 (residues 248-256) located on the surface-exposed loop L3 (Bergmann et al., 2003, 2005; Ehinger et al., 2004), while the C-terminal lysine residue(s) (BS1) is either not or only marginally involved. In particular, within the Plgbinding site BS2 of pneumococcal enolase Lys-251, Lys-254 and Glu-252 are critical for Plg binding (Ehinger et al., 2004). The homology model of the B. lactis BI07 enolase indicated that the protein possesses a structural homologue of both the internal Plg-binding site BS2 of pneumococcal enolase and the C-terminal lysine that constitutes the Plgbinding site BS1. Site-direct mutagenesis of Lys-251, Glu252 and Lys-255 within the BS2 homologue of B. lactis BI07 enolase impaired its Plg-binding activity. In contrast, the deletion of the B. lactis BI07 enolase C-terminal lysine 
did not have any impact on Plg interaction. Taken together, our data demonstrate that the interaction between the $B$. lactis BI07 enolase and human Plg involves the internal Plg-binding site homologous to the BS2 site of pneumococcal enolase. In particular, as in the case of pneumococcal enolase (Ehinger et al., 2004), the positively charged residues Lys-251 and Lys-255, and the negatively charged Glu-252, are vital for Plg interaction. Disruption of the enolase gene would provide in vivo proof of its role as a Plg receptor; however, the presence of only one bifidobacterial enolase gene, which is essential for bacterial survival, renders the construction of a viable enolasedefective B. lactis BI07 mutant impossible.

There is a growing number of reports concerning the expression of cytoplasmic housekeeping proteins on the bacterial cell surface of Gram-positive micro-organisms (Pancholi, 2001; Pancholi \& Chhatwal, 2003; Schaumburg et al., 2004; Sijbrandi et al., 2005; Lee et al., 2006; Antikainen et al., 2007a; Knaust et al., 2007). Although their mechanism of secretion still remains unclear, localized on the bacterial cell surface these multifunctional proteins acquire a 'moonlighting' function (Jeffery, 1999), with a role in the interaction process with the host. We believe that this is the first report of the localization of enolase on the cell surface of four species of Bifidobacterium, a health-promoting member of the human intestinal microbiota. Interestingly, the presence of surface enolase has been recently reported for two species belonging to the gut commensal genus Lactobacillus (Antikainen et al., 2007a; Castaldo et al., 2009). However, while the Lactobacillus crispatus surface enolase is a receptor for human Plg, the Lactobacillus plantarum surface enolase is a fibronectin-binding protein. Acting as a human $\mathrm{Plg}$ receptor, the bifidobacterial surface enolase may play a role in the interaction with the host. Although it will be necessary to screen for the presence of surface enolases in other bifidobacterial species, our findings raise the question of the impact of glycolytic enzymes in the biology of the Bifidobacterium-host interaction. In particular, concerning enolase, further studies are justified to investigate its capability to interact with extracellular matrix proteins such as laminin and fibronectin, as already reported for the enolases from Lactobacillus, Streptococcus and Staphylococcus (Antikainen et al., 2007a).

\section{REFERENCES}

Altschul, S. F., Gish, W., Miller, W., Myers, E. W. \& Lipman, D. J. (1990). Basic local alignment search tool. J Mol Biol 215, 403-410.

Altschul, S. F., Madden, T. L., Schaffer, A. A., Zhang, J., Zhang, Z., Miller, W. \& Lipman, D. J. (1997). Gapped BLAST and PSI-BLAST: a new generation of protein database search programs. Nucleic Acids Res 25, 3389-3402.

Antikainen, J., Kuparinen, V., Lähteenmäki, K. \& Korhonen, T. K. (2007a). Enolases from Gram-positive bacterial pathogens and commensal lactobacilli share functional similarity in virulenceassociated traits. FEMS Immunol Med Microbiol 51, 526-534.
Antikainen, J., Hurmalainen, V., Lähteenmäki, K. \& Korhonen, T. K. (2007b). pH-dependent association of enolase and GAPDH of Lactobacillus crispatus with the cell wall and lipoteichoic acid. J Bacteriol 189, 4539-4543.

Bergmann, S. \& Hammerschmidt, S. (2007). Fibrinolysis and host response in bacterial infections. Thromb Haemost 98, 512-520.

Bergmann, S., Rohde, M., Chhatwal, G. S. \& Hammerschmidt, S. (2001). $\alpha$-Enolase of Streptococcus pneumoniae is a plasmin(ogen)binding protein displayed on the bacterial cell surface. Mol Microbiol 40, 1273-1287.

Bergmann, S., Wild, D., Diekmann, O., Frank, R., Bracht, D., Chhatwal, G. S. \& Hammerschmidt, S. (2003). Identification of a novel plasmin(ogen)-binding motif in surface displayed alpha-enolase of Streptococcus pneumoniae. Mol Microbiol 49, 411423.

Bergmann, S., Rohde, M., Preissner, K. T. \& Hammerschmidt, S. (2005). The nine residue plasminogen-binding motif of the pneumococcal enolase is the major cofactor of plasmin-mediated degradation of extracellular matrix, dissolution of fibrin and transmigration. Thromb Haemost 94, 304-311.

Boël, G., Pichereau, V., Mijakovic, I., Mazé, A., Poncet, S., Gilet, S., Giard, J. C., Hartke, A., Auffray, Y. \& Deutscher, J. (2004). Is 2phosphoglycerate-dependent automodification of bacterial enolases implicated in their export? J Mol Biol 337, 485-496.

Candela, M., Bergmann, S., Vici, M., Vitali, B., Turroni, S., Eikmanns, B. J., Hammerschmidt, S. \& Brigidi, P. (2007). Binding of human plasminogen to Bifidobacterium. J Bacteriol 189, 5929-5936.

Candela, M., Miccoli, G., Bergmann, S., Turroni, S., Vitali, B., Hammerschmidt, S. \& Brigidi, P. (2008). Plasminogen-dependent proteolytic activity in Bifidobacterium lactis. Microbiology 154, 24572462.

Castaldo, C., Vastano, V., Siciliano, R. A., Candela, M., Vici, M., Muscariello, L., Marasco, R. \& Sacco, M. (2009). Surface displaced alfa-enolase of Lactobacillus plantarum is a fibronectin binding protein. Microb Cell Fact 8, 14.

Claverys, J. P. \& Havarstein, L. S. (2007). Cannibalism and fratricide: mechanisms and raisons d'être. Nat Rev Microbiol 5, 219-229.

Collen, D. \& Verstraete, M. (1975). Molecular biology of human plasminogen. II. Metabolism in physiological and some pathological conditions in man. Thromb Diath Haemorrh 34, 403-408.

Crowe, J. D., Sievwright, I. K., Auld, G. C., Moore, N. R., Gow, N. A. \& Booth, N. A. (2003). Candida albicans binds human plasminogen: identification of eight plasminogen-binding proteins. Mol Microbiol 47, 1637-1651.

Cuff, J. A., Clamp, M. E., Siddiqui, A. S., Finlay, M. \& Barton, G. J. (1998). JPRED: a consensus secondary structure prediction server. Bioinformatics 14, 892-893.

Derbise, A., Song, Y. P., Parikh, S., Fischetti, V. A. \& Pancholi, V. (2004). Role of the C-terminal lysine residues of streptococcal surface enolase in Glu- and Lys-plasminogen-binding activities of group A streptococci. Infect Immun 72, 94-105.

Ehinger, S., Schubert, W. D., Bergmann, S., Hammerschmidt, S. \& Heinz, D. W. (2004). Plasmin(ogen)-binding alpha-enolase from Streptococcus pneumoniae: crystal structure and evaluation of plasmin(ogen)-binding sites. J Mol Biol 343, 997-1005.

Esgleas, M., Li, Y., Hancock, M. A., Harel, J., Dubreuil, J. D. \& Gottschalk, M. (2008). Isolation and characterization of alphaenolase, a novel fibronectin-binding protein from Streptococcus suis. Microbiology 154, 2668-2679.

Guarner, F. \& Malagelada, J. R. (2003). Gut flora in health and disease. Lancet 361, 512-519. 
Hurmalainen, V., Edelman, S., Antikainen, J., Baumann, M., Lähteenmäki, K. \& Korhonen, T. K. (2007). Extracellular proteins of Lactobacillus crispatus enhance activation of human plasminogen. Microbiology 153, 1112-1122.

Jeffery, C. J. (1999). Moonlighting proteins. Trends Biochem Sci 24, 8-11.

Klijn, A., Mercenier, A. \& Arigoni, F. (2005). Lessons from the genomes of bifidobacteria. FEMS Microbiol Rev 29, 491-509.

Knaust, A., Weber, M. V., Hammerschmidt, S., Bergmann, S., Frosch, M. \& Kurzai, O. (2007). Cytosolic proteins contribute to surface plasminogen recruitment of Neisseria meningitidis. J Bacteriol 189, 3246-3255.

Kolberg, J., Aase, A., Bergmann, S., Herstad, T. K., Rødal, G., Frank, R., Rohde, M. \& Hammerschmidt, S. (2006). Streptococcus pneumoniae enolase is important for plasminogen binding despite low abundance of enolase protein on the bacterial cell surface. Microbiology 152, 1307-1317.

Lähteenmäki, K., Edelman, S. \& Korhonen, T. K. (2005). Bacterial metastasis: the host plasminogen system in bacterial invasion. Trends Microbiol 13, 79-85.

Laskowski, R. A., MacArthur, M. W., Moss, D. S. \& Thornton, J. M. (1993). PROCHECK: a program to check the stereochemical quality of protein structures. J Appl Crystallograph 26, 283-291.

Lee, J. H., Kang, H. K., Moon, Y. H., Cho, D. L., Kim, D., Choe, J. Y., Honzatko, R. \& Robyt, J. F. (2006). Cloning, expression and characterization of an extracellular enolase from Leuconostoc mesenteroides. FEMS Microbiol Lett 259, 240-248.

Marti-Renom, M. A., Stuart, A. C., Fiser, A., Sanchez, R., Melo, F. \& Sali, A. (2000). Comparative protein structure modeling of genes and genomes. Annu Rev Biophys Biomol Struct 29, 291-325.

Pancholi, V. (2001). Multifunctional $\alpha$-enolase: its role in diseases. Cell Mol Life Sci 58, 902-920.

Pancholi, V. \& Chhatwal, G. S. (2003). Housekeeping enzymes as virulence factors for pathogens. Int J Med Microbiol 293, 391-401.

Pancholi, V. \& Fischetti, V. A. (1998). Alpha-enolase, a novel strong plasmin(ogen) binding protein on the surface of pathogenic streptococci. J Biol Chem 273, 14503-14515.

Parkkinen, J. \& Korhonen, T. K. (1989). Binding of plasminogen to Escherichia coli adhesion proteins. FEBS Lett 250, 437-440.

Pettersen, E. F., Goddard, T. D., Huang, C. C., Couch, G. S., Greenblatt, D. M., Meng, E. C. \& Ferrin, T. E. (2004). UCSF chimera a visualization system for exploratory research and analysis. J Comput Chem 25, 1605-1612.

Redlitz, A., Fowler, B. J., Plow, E. F. \& Miles, L. A. (1995). The role of an enolase-related molecule in plasminogen binding to cells. Eur $J$ Biochem 227, 407-415.

Saksela, O. \& Rifkin, D. B. (1988). Cell-associated plasminogen activation: regulation and physiological functions. Annu Rev Cell Biol 4, 93-126.
Sanderson-Smith, M. L., Walker, M. J. \& Ranson, M. (2006). The maintenance of high affinity plasminogen binding by group A streptococcal plasminogen-binding M-like protein is mediated by arginine and histidine residues within the a1 and a2 repeat domains. J Biol Chem 281, 25965-25971.

Sanderson-Smith, M. L., Dowton, M., Ranson, M. \& Walker, M. J. (2007). The plasminogen-binding group A streptococcal M proteinrelated protein Prp binds plasminogen via arginine and histidine residues. J Bacteriol 189, 1435-1440.

Schaumburg, J., Diekmann, O., Hagendorff, P., Bergmann, S., Rohde, M., Hammerschmidt, S., Jansch, L., Wehland, J. \& Karst, U. (2004). The cell wall subproteome of Listeria monocytogenes. Proteomics 4, 2991-3006.

Schell, M. A., Karmirantzou, M., Snel, B., Vilanova, D., Berger, B., Pessi, G., Zwahlen, M. C., Desire, F., Bork, P. \& other authors (2002). The genome sequence of Bifidobacterium longum reflects its adaptation to the human gastrointestinal tract. Proc Natl Acad Sci U S A 99, 14422-14427.

Shevchenko, A., Wilm, M., Vorm, O. \& Mann, M. (1996). Mass spectrometric sequencing of proteins silver-stained polyacrylamide gels. Anal Chem 68, 850-858.

Sijbrandi, R., Den Blaauwen, T., Tame, J. R. H., Oudega, B., Luirink, J. \& Otto, B. R. (2005). Characterization of an iron-regulated alphaenolase of Bacteroides fragilis. Microbes Infect 7, 9-18.

Thompson, J. D., Higgins, D. G. \& Gibson, T. J. (1994). CLUSTAL W: improving the sensitivity of progressive multiple sequence alignment through sequence weighting, position-specific gap penalties and weight matrix choice. Nucleic Acids Res 22, 4673-4680.

Vassalli, J. D., Sappino, A. P. \& Belin, D. (1991). The plasminogen activator/plasmin system. J Clin Invest 88, 1067-1072.

Ventura, M., O'Connell-Motherway, M., Leahy, S., Moreno-Munoz, J. A., Fitzgerald, G. F. \& van Sinderen, D. (2007). From bacterial genome to functionality; case bifidobacteria. Int J Food Microbiol 120, $2-12$.

Ventura, M., O'Flaherty, S., Claesson, M. J., Turroni, F., Klaenhammer, T. R., van Sinderen, D. \& O'Toole, P. W. (2009). Genome-scale analyses of health-promoting bacteria: probiogenomics. Nat Rev Microbiol 7, 61-71.

Willard, L., Ranjan, A., Zhang, H., Monzavi, H., Boyko, R. F., Sykes, B. D. \& Wishart, D. S. (2003). VADAR: a web server for quantitative evaluation of protein structure quality. Nucleic Acids Res 31, 33163319.

Zambelli, B., Turano, P., Musiani, F., Neyroz, P. \& Ciurli, S. (2009). $\mathrm{Zn}^{2+}$-linked dimerization of UreG from Helicobacter pylori, a chaperone involved in nickel trafficking and urease activation. Proteins 74, 222-239.

Zhang, L., Seiffert, D., Fowler, B. J., Jenkins, G. R., Thinnes, T. C., Loskutoff, D. J., Parmer, R. J. \& Miles, L. A. (2002). Plasminogen has a broad extrahepatic distribution. Thromb Haemost 87, 493-501.

Edited by: H. J. Flint 